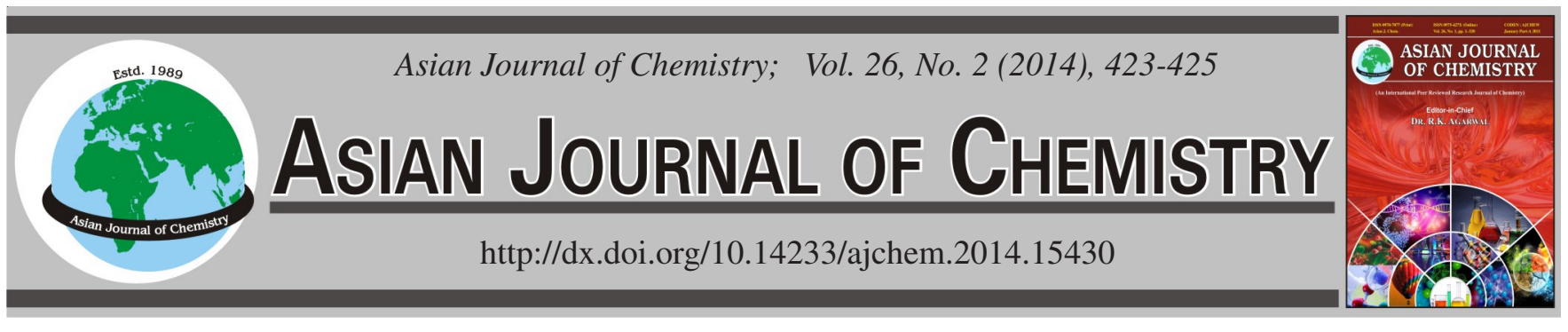

\title{
Determination of Phenols in Water by Modified Polymer Extraction-Fluorine Derivative Gas Chromatography-Negative Chemical Ionization Mass Spectrometry
}

\author{
Li Zhang, Chen-Ling Zhang, Yong-Tao Zhang ${ }^{*}$, Jian-Ye Gui and XiaO-Ya Li
}

Institute of Hydrogeology and Environmental Geology, Chinese Academy of Geological Science, Zhengding 050803, P.R. China

*Corresponding author: E-mail: icpzytws@126.com

A method of phenol extraction by modified styrene-divinylbenzene polymer was established. We introduced fluorine element into phenols to enhance the electronegativity and the analytes were determined by gas chromatography-negative chemical ionization mass spectrometry (GC-NCI-MS), with detection limits lower than $0.10 \mu \mathrm{g} / \mathrm{L}$. The phenols were extracted among $\mathrm{pH} 2-4$ and eluted by $3 \mathrm{~mL}$ acetone and $5 \mathrm{~mL}$ dichloromethane; they were derivatized under the conditions of $20 \mu \mathrm{L} \mathrm{K}_{2} \mathrm{CO}_{3}(30 \%)$ and 2,4,5,6-pentafluoro-benzyl bromide $(5 \%)$; derivative products were purified by $6 \mathrm{~mL}$ toluene/hexane $(6: 1, \mathrm{v} / \mathrm{v})$; analytes were analyzed qualitatively and quantitatively by GC-NCI-MS. The coefficient correlations were all higher than 0.99 and detection limits were in the range of $0.03-0.09 \mu \mathrm{g} / \mathrm{L}$. The recovery of phenols was between 65 and $94 \%$ with relative standard deviations varied from 5 and $17 \%$.

Keywords: Phenols, Modified polymer, Fluorine, Negative chemical ionization mass spectrometry.

\section{INTRODUCTION}

Poly(styrene-divinylbenzene) resin are divided by polar and nonpolar ones. Styrene-divinyl benzene polymer resin of nonpolar resin, could absorb hydrophobic matter and thus is used in solid phase extraction of polar organics ${ }^{1}$, which, especially modified styrene-divinylbenzene (chemically modified polymer) is used as filter and generates solid phase extraction means. Modified styrene-divinylbenzene polymer, the surface of which is non-polar, high crosslinked and high specific surface area, can tolerate extreme $\mathrm{pH}$ environments, which ensures the accuracy of the result. Compared with polar compounds extraction by silica gel adsorbents ${ }^{2,3}$, styrene-divinylbenzene polymer extraction is simpler, easier choice of eluting reagent, higher extraction recovery and more stability, etc.

Gas chromatography-negative chemical ionization mass spectrometry (GC-NCI-MS) could dramatically improve analytical sensitivity due to unique selectivity to high negative substance and soft ionization, but cannot be applied in phenols detection of weak electrical negativity. In Pauling scale, specified fluoride has the highest electronegativity (the electronegativity of fluorine is defined 4.0 and other non-metallic elements has relative elctronegativity). Under certain conditions, the introduction of fluorine in phenolic compounds could significantly improved its electronegativity. In this study, we introduced pentafluoro group into phenols by derivatization reaction, the change of volatility made its chromatographic separation easier, the increase of electonegativity enhanced its response signal. Compared with other methods ${ }^{2-5}$, negative chemical ionization mass spectrometry detection was accurate with low background and low detection limit. All detection limits were lower than $0.10 \mu \mathrm{g} / \mathrm{L}$.

\section{EXPERIMENTAL}

Main instruments and reagents: Gas chromatographymass spectrometry (GC-MSQP2010, Shimadzu); Ionization source: negative chemical ionization (NCI); solid phase extraction installation; Water-bath; Evaporator; Varian $\mathrm{C}_{18}$ column (500 mg/6 mL); Waters Oasis HLB column (40 mg/3cc); Merck LiChrolut EN column (200 mg/3 mL); Varian Bond Elut PPL column (200 mg/3 mL); Varian ( $1 \mathrm{~g} / 6 \mathrm{~mL})$. Dichloromethane; hexane; toluene; acetone; phosphoric acid; 2,3,4,5,6pentafluoro-benzyl bromide $(99.5 \%)$; potassium carbonate (GR); sodium sulphate. Standards: phenol; 2-methylphenol; 4-methylphenol; 2,4-dimethylphenol; 2,3,4,6-tetrachlorophenol; 2,6-dinitro-4-methylphenol; 2,4-dinitrophenol.

Sample extraction: Elut PPL column was conditioned by $2 \mathrm{~mL}$ dichloromethane, $2 \mathrm{~mL}$ methanol and $2 \mathrm{~mL}$ water in succession. A $200 \mathrm{~mL}$ water sample, adjusted to $\mathrm{pH} 2-4$ by phosphoric acid $(1+1)$, was controlled in the column with flow rate $4 \mathrm{~mL} / \mathrm{min}$. Then it was eluted successively by $3 \mathrm{~mL}$ acetone and $5 \mathrm{~mL}$ dichloromethane. The eluent was evaporated to $0.5 \mathrm{~mL}$ after dehydrated by sodium sulphate. 
Derivatization: The concentrated liquid was transferred to derivative flask with $1.5 \mathrm{~mL}$ acetone and then added acetone to $4 \mathrm{~mL}, 20 \mu \mathrm{L} \mathrm{K}_{2} \mathrm{CO}_{3}(30 \%), 100 \mu \mathrm{L} 2,4,5$,6-pentafluorobenzyl bromide $(5 \%)$ at $60{ }^{\circ} \mathrm{C}$ for $50 \mathrm{~min}$. Removed the derivative bottle, The products were vaporated to $0.5 \mathrm{~mL}$, then re-dissolved with $2.0 \mathrm{~mL}$ hexane and vaporated to $0.5 \mathrm{~mL}$ at last.

Purification: Silica-gel column was conditioned by 4-5 $\mathrm{mL}$ hexane previously. Derivative products of 1.4 , re-dissolved with $2.0 \mathrm{~mL}$ hexane, were purified and eluted by $6 \mathrm{~mL}$ toluene/ hexane $(6: 1, v / v)$ in the silica-gel column. The final extraction was injected to GC-NCI-MS.

GC-NCI-MS analysis: Capillary column: HP-5MS (30 $\mathrm{m} \times 0.25 \mathrm{~mm} \times 0.25 \mu \mathrm{m})$. Programmed temperature: started at $90{ }^{\circ} \mathrm{C}$, increased by $25^{\circ} \mathrm{C} / \mathrm{min}$ to $300{ }^{\circ} \mathrm{C}$ and held for 1.6 min. Injector temperature: $220^{\circ} \mathrm{C}$; injection mode: splitless; injection volume: $1.0 \mu \mathrm{L}$. MS: ion source: negative chemical ionization (NCI); reagent gas: methane $\left(\mathrm{CH}_{4}\right)$; scan mode: selective ion monitoring (SIM); ionization energy: $70 \mathrm{eV}$; ion source temperature: $200{ }^{\circ} \mathrm{C}$; interface temperature: $220^{\circ} \mathrm{C}$.

\section{RESULTS AND DISCUSSION}

Polymers study: Strong hydrophobic silica matrix adsorbent had weak retention of polar compounds, of which as $\mathrm{C}_{18}$ column filter had poor absorption of phenols. Multipolymer made by $\mathrm{N}$-vinylpyrrolidone and divinylbenzene. These two monomers by certain ratio had hydrophilic lipophilic ester group on the surface, thus had wide conservation but weak conservation to certain polar compounds. Waters Oasis HLB column made the above as filter's recovery to nitrophenolic adsorption was less than $40 \%$. Styrene-divinylbenzene copolymer without chemical modification showed non-polar performance on the surface and characteristics of adsorption of hydrophobic substances. Merck LiChrolut EN column with the above as the filter could absorb phenols but low absorption to nitrophenol. Functionalized, highly crosslinked and tolerant to extreme $\mathrm{pH}$ environment styrene-divinylbenzene spherical polymer is another highly selective adsorption resins. Its relative large specific surface area resulted from derivative nonpolar surface and highly crosslinked (600-1000 $\left.\mathrm{m}^{2} / \mathrm{g}\right)$ could get high phenolic compounds recovery, Varian Bond Elut PPL column with which as the filter got $70 \%$ recovery or higher of phenols. The concentration of water samples (pure water with spiked samples) was $0.5 \mu \mathrm{g} / \mathrm{L}$. The recovery of different small column showed in Table-1.

Extraction: Compared with the silica gel adsorbent, modified styrene-divinylbenzene polymer, can tolerate extreme $\mathrm{pH}$ environments. So the sample was adjusted at $\mathrm{pH} 2-4$, under which phenols are non ionic and the recovery can be guaranteed. In addition, the adsorption on the modified polymer is not permanent. Once there is some organic solvent, the adsorpted will be eluted ${ }^{1}$. Therefore, a greater range of solvents could be used as eluting reagent. Considering phenol volatility, other solvents with low boiling point, acetone and dichloromethane were selected.

Derivatization: The conditions of derivatization time, temperature, catalyst and solvent were optimized according to the response in gas chromatography.

Derivation time and temperature: Our experiments suggested that, peak areas of derivative products increased variably upon extension of derivation time within $20 \mathrm{~min}$ and at 30 min they reached the maximum except two nitrophenols. When derivation action lasted $50 \mathrm{~min}$, all products get the strongest response. As for reaction temperature, it was selected at $50-60{ }^{\circ} \mathrm{C}$ to avoid phenol volatilization. Investigations suggested that derivation action should be developed at 50$60{ }^{\circ} \mathrm{C}$ for $50 \mathrm{~min}$.

Catalyst: In the derivative reaction, $\mathrm{K}_{2} \mathrm{CO}_{3}$ acted as a catalyst. It was found that, the catalytic effect of $\mathrm{K}_{2} \mathrm{CO}_{3}(30 \%$, $50 \mu \mathrm{L})$ was better than $\mathrm{K}_{2} \mathrm{CO}_{3}(10 \%, 200 \mu \mathrm{L})$ even if the adding amount of the latter was larger than the former. That is because presence of water resulted in the hydrolysis of derivative reagents and derivatives ${ }^{6}$. Therefore, it was necessary to minimize water introduction before and in the derivatization procedure. $\mathrm{K}_{2} \mathrm{CO}_{3}$ with high concentration (30\%) was chosen and experimented on the quantity, which fixed catalyst $\mathrm{K}_{2} \mathrm{CO}_{3}$ (30\%) quantity to $20 \mu \mathrm{L}$.

Derivation solvent: Three solvents, dichloromethane, $n$-hexane and acetone were tested in derivation reaction. We found that, preferably derivative effects and a lower RSD (less than $17 \%$ ) were achieved in acetone. It is associated with the solubility of $\mathrm{K}_{2} \mathrm{CO}_{3}$ solution in organic solvents. As it is miscible with acetone, catalytic effect and reproducible results were preferably demonstrated.

Purification: The excess 2,4,5,6-pentafluoro-benzyl bromide was removed by evaporation. After that, derivative products were purified in the silica-gel column, rinsed by $2 \mathrm{~mL}$ hexane to remove most nonpolar compounds. The elution solvent is an important parameter that affects the purification performance, so the proportions of toluene and hexane were investigated (Table-2). In the condition of toluene/hexane (1:3, $\mathrm{v} / \mathrm{v})$ or $(2: 3, \mathrm{v} / \mathrm{v})$, all compounds except two nitrophenols were purified and eluted well. The recovery of 2,4-dinitrophenol was less than $10 \%$ with toluene/hexane $(1: 1, \mathrm{v} / \mathrm{v})$. With the increase of toluene proportion, elution ratio of nitrophenol increased gradually. The recoveries were all higher than $70 \%$

TABLE-1

INFLUENCE OF DIFFERENT COLUMNS TO RECOVERY (\%)

\begin{tabular}{lcccc}
\hline \multirow{2}{*}{ Compounds } & \multicolumn{4}{c}{ Recovery (\%) } \\
\cline { 2 - 5 } & Varian $\mathrm{C}_{18}$ & Waters Oasis HLB & Merck Li Chrolut EN & Varian Bond Elut PPL \\
\hline Phenol & 16.9 & 86.8 & 88.6 & 84.2 \\
2-Methylphenol & 24.8 & 81.5 & 79.8 & 87.7 \\
4-Methylphenol & 26.2 & 87.1 & 76.8 & 91.4 \\
2,4-Dimethylphenol & 64.8 & 86.8 & 80.1 & 87.6 \\
2,3,4,6-Tetrachlorophenol & 30.2 & 52.1 & 66.4 & 78.1 \\
2,6-Dinitro-4-methylphenol & 10.4 & 29.7 & 49.8 & 68.9 \\
2,4-Dinitrophenol & 6.8 & 33.1 & 54.7 & 70.6 \\
\hline
\end{tabular}




\begin{tabular}{lcccc}
\hline \multicolumn{5}{c}{ TABLE-3 } \\
& \multicolumn{5}{c}{ MAIN QUALITATIVE AND QUANTITATIVE PARAMETERS OF DERIVATIVE PRODUCTS } \\
\hline \multicolumn{1}{c}{ Compounds } & Retention time $(\mathrm{min})$ & m.w. $(\mathrm{m})$ & Quantitative ion $(\mathrm{m} / \mathrm{z})$ & Reference ion $(\mathrm{m} / \mathrm{z})$ \\
\hline Phenol & 5.07 & 274 & 93 & 94 \\
2-Methylphenol & 5.34 & 288 & 107 & 108 \\
4-Methylphenol & 5.52 & 288 & 107 & 108 \\
2,4-Dimethylphenol & 5.74 & 302 & 121 & 122 \\
2,3,4,6-Tetrachlorophenol & 7.76 & 412 & 231 & 229,233 \\
2,6-Dinitro-4-methylphenol & 8.71 & 378 & 197 & 167 \\
2,4-Dinitrophenol & 9.49 & 364 & 183 & 153 \\
\hline
\end{tabular}

TABLE-4

CORRELATION COEFFICIENT, RECOVERY AND RELATIVE STANDARD DEVIATION (RSD, $\mathrm{n}=7$ )

\begin{tabular}{lcc|cc|cc}
\hline \multirow{2}{*}{ Compounds } & \multicolumn{2}{c|}{$0.1 \mu \mathrm{g} / \mathrm{L}$} & \multicolumn{2}{c|}{$0.5 \mu \mathrm{g} / \mathrm{L}$} & \multicolumn{2}{c}{$2 \mu \mathrm{g} / \mathrm{L}$} \\
\cline { 2 - 7 } & Recovery $(\%)$ & RSD $(\%)$ & Recovery (\%) & RSD (\%) & Recovery $(\%)$ & RSD (\%) \\
\hline Phenol & 70.1 & 6.7 & 86.6 & 5.5 & 88.2 & 5.0 \\
2-Methylphenol & 68.8 & 5.9 & 84.7 & 6.2 & 83.9 & 6.3 \\
4-Methylphenol & 80.3 & 7.1 & 87.2 & 5.6 & 94.0 & 4.9 \\
2,4-Dimethylphenol & 81.6 & 7.9 & 85.6 & 7.3 & 84.1 & 6.7 \\
2,3,4,6-Tetrachlorophenol & 76.1 & 8.6 & 86.1 & 9.0 & 87.8 & 9.3 \\
2,6-Dinitro-4-methylphenol & 64.9 & 15.6 & 68.2 & 11.4 & 68.8 & 13.0 \\
2,4-Dinitrophenol & 69.5 & 16.8 & 73.3 & 12.8 & 71.3 & 11.2 \\
\hline
\end{tabular}

\begin{tabular}{lcccc} 
TABLE-2 \\
INFLUENCE OF DIFFERENT ELUTING \\
SOLVENTS TO RECOVERY (\%) \\
\cline { 2 - 5 } \multicolumn{4}{c}{ Compounds } & \multicolumn{4}{c}{ Recovery } \\
\cline { 2 - 5 } & $(1: 3)$ & $(2: 3)$ & $(1: 1)$ & $(6: 1)$ \\
\hline Phenol & 80.0 & 81.7 & 85.7 & 84.6 \\
2-Methylphenol & 79.8 & 86.2 & 86.6 & 83.9 \\
4-Methylphenol & 80.2 & 86.9 & 87.0 & 86.8 \\
2,4-Dimethylphenol & 83.9 & 84.0 & 87.8 & 89.9 \\
2,3,4,6-Tetrachlorophenol & 84.4 & 86.6 & 90.1 & 86.7 \\
2,6-Dinitro-4-methylphenol & - & - & 69.0 & 68.2 \\
2,4-Dinitrophenol & - & - & 9.24 & 78.4 \\
\hline
\end{tabular}

with toluene/hexane $(6: 1, \mathrm{v} / \mathrm{v})$. Therefore, the elution solvent was chosen toluene/hexane $(6: 1, v / v)$. Since different elution conditions resulted in different concentration time and chromatographic background values, eluting solvent ratio in purification was chosen according to the analysis requires determining.

High selection of negative chemical ionization: In pauling scale, the electronegativity of fluorine is defined 4 and other non-metallic elements, oxygen, chlorine, nitrogen, carbon, hydrogen decreased successively. It is insufficient to generate strong signal in the negative chemical source if compounds don't contain the fluorine element. Introduction of 5 fluorine elements (pentafluoro group) made the phenols more electronegative and separated within $10 \mathrm{~min}$. The response of MS enhanced and the detection limits several times lower than that of GC-MS (EI source). In addition, compounds may produce [M-1] fragments ( $\mathrm{M}$ for molecular weight) in the soft ionization condition. So the NCI detection mode was more selective and more accurate. Moreover, introduction of pentafluoro group made phenols more volatile and the chromatographic separation finished within $10 \mathrm{~min}$. The main qualitative and quantitative parameters were list in Table-3.

Linearity, limit of detection and limit of quantification: These seven phenols could be determined in the 10.0-500.0 $\mu \mathrm{g} / \mathrm{L}$ range with $\mathrm{r}^{2}>0.99$. Limits of detection (LOD, $\mathrm{S} / \mathrm{N}=3$ ) and limits of quantitation ( $\mathrm{LOQ}, \mathrm{S} / \mathrm{N}=10$ ) were $0.03-0.09$ and $0.1-0.3 \mu \mathrm{g} / \mathrm{L}$, respectively.

Recovery and precision: A spiking study was conducted on a mixed wastewater sample from coking plant (containing phenol and 2,4-dimethylphenol) and pharmaceutical factory (nitrophenol contained). The spiked sample at three levels $(0.1$, 0.5 and $2 \mu \mathrm{g} / \mathrm{L}$ ) were extracted accordingly (concentrated by 200 times, $20 \mu \mathrm{g} / \mathrm{L}, 100 \mathrm{~g} / \mathrm{L}$ and $400 \mu \mathrm{g} / \mathrm{L}$ actually). The recoveries and relative standard deviations (RSDs, $n=7$ ) are determined for seven times, shown in Table-4.

\section{Conclusion}

Solid phase extraction by modified styrene-divinylbenzene polymer is used for high extraction recovery and reproducibility due to the characteristics, such as non-polar surface, high specific surface area, strong stability, etc. Introduction of fluorine increased electronegativity of phenols, enhanced response in GC-NCI-MS and thus lowered the detection limits.

\section{ACKNOWLEDGEMENTS}

The article was supported by the Fundamental Research Funds for the Institute of Hydrogeology and Environmental Geology, ChineseAcademy of Geological Science (SK201204).

\section{REFERENCES}

1. W.-Q. Huang, Adsorption Sep. Mater., 34, 58 (2005).

2. Y. Bai-Juan, J. Feng-Hua, X. Xiao-Qin, C. Jun-Hui and F.S.C. Lee, Chin. J. Anal. Chem., 35, 633 (2007).

3. Q.-F. Hu, G.-Y. Yang, Z.-J. Huang and J.-Y. Yi, Chin. J. Anal. Chem., 30, 560 (2002).

4. J.-C. Wang, L. Xiong, H.-J. Zhang and J.-P. Chen, Chin. J. Chromatogr., 29, 1160 (2011).

5. Q.-H. Yang, X.-Y. Cheng, P. Yang, S. Qian and D.-Z. Dan, Chin. J. Anal. Chem., 39, 1208 (2011).

6. T.-M. Xie, Techniq. Oper. Manage. Environ. Anal., 108 (2008). 